\title{
The Problem Frames Approach to a Virtual Laboratory Conception
}

\author{
Nicolas Pagès, Monique Noirhomme-Fraiture \\ Institut d'Informatique, FUNDP \\ 21, rue Grandgagnage, 5000, Namur, Belgium \\ mno@info.fundp.ac.be
}

\begin{abstract}
This paper presents a virtual laboratory's conception. It is based on the problem frames approach and involves tke adaptation to computer assisted learning environments. It enphasizes the necessity of defining a certain number of new problem frames in order to adapt it to a learning environment, and particularly to simulations. We present the application of this conception method to the SAI project.
\end{abstract}

Keywords: Interactivity, virtual laboratory, problem frames, learning environment, experience.

\section{Introduction}

Computer assisted learning environments are designed in order to help human learning, or to help a learner to construct its knowledge [20]. The conception of a computer learning environment (CLE) is often, a difficult and particular problem. According to [20], the question of CLE engineering can be asked in the following terms: what elements does the designer have in order to organize the design process of that kind of environment? Only a few answers to that question currently exist. Indeed, a great number of works and systems are ad hoc. According to [10], "the construction analysis of these systems shows little consensus for what concerns the main principles" (according to the authors, the system must be founded on practice observation of the teachers, on the education or cognitive science phychologists' works, etc.). Furthermore, the arguments proposed to justify their choices are not widely accepted.

That situation is also treated in [17], where, even the field of virtual laboratories is specifically addressed, the same conclusions are reached: "An important number of institutions work on the development of virtual labs for the web. It is to be noted that articles about virtual labs are not numerous, when the number of sites of this type increases steadily. In this field, a very open and experimental approach seems to have been adopted, which gives rise to a multitude of the most diverse realizations. That kind of approach is a characteristic of the web".

Virtual laboratories are not necessarily web based. Since the seventies, with the well known PLATO system that popularised the use of virtual labo- ratories using computer facilities, this approach is used. The PLATO Learning System have over 40 years of experience and a research basis that is among the strongest in the industry. Access the documents in the web page of the system [18] shows the student success as well as the research behind the award-winning products and services. However, there are many opositors, and the importance of the opositions depend upon the subject of the learning material. An evaluation of the advantages of a virtual environment in physiology is presented in [12] with the experience of the work presented in [13], [14] and [15].

In this paper, the focus is on the virtual laboratory conception problem, as a learning environment. This text is structured in the following way:

1. Firstly is presented the SAI project and it is given a brief description of the different experiments involved in the project.

2. Then, the learning issues are addressed.

3. After that, we will precise the concept of simulation adopted in the project and the reasons that justify the choice of that methodology as a learning support.

4. We will next proceed towards the problem frames approach, which will first be explained, and then applied to our project. That will allow us to proceed to the decomposition into subproblems described in that approach. The existing frame analysis problem reveals the lack of ones that be adapted to CLE's. Thus, it is proposed new ones.

5. Then it is possible to study three subproblems that result from our analysis. 
6. We will then come through a certain number of recommendations resulting from that analysis, and their application to our project.

7. After that we present the solutions we have found to address these three subproblems. Finally, conclusions are presented.

\section{The SAI Project}

\subsection{Presentation}

The objective of the SAI project is to offer to a used not weel familiarizes with computer tools, a very simple and uer friendly tool allowing to reproduce real experiments and to make them available to students through a network. It is designed to address to two distinct types of users: first, the professor or author, and second, the student or learner. This distinction is the same adopted by the MAI project [11]. For both users, no particular expertise is required in the field of computer science. Two different interfaces are designed, one for each user. Each of these offers some possibilities and options, that vary according to whether the user is a professor or a student.

\subsection{Three fields for the experiences}

This project is articulated around three particular experiences that come under the fields of biology, chemistry and physics. These are the ion exchange chromatography, the Newton laws and the fluid mechanics in stationary regime.

- Chromatography: this is a physic-chemical analysis that separates the constituents of a mixture. The constituents are moved through a pipe by a mobile phase along a stationary phase, and they are separated thanks to the selective repartition of the solutions between these two phases. The realisation of this experience demands a certain amount of time, which among other elements justifies its conversion to the virtual format.

- The Newton laws : many physics experiences are already available on the Internet, but most of these concern electricity. Furthermore, the Newton laws are rather abstract and difficult to handle for students. Being able to directly visualize the effects of the forces should allow them to handle those theoretical notions with more facility.

- Fluid mechanics : the goal of this experience is to understand the relatively abstract notions of debit and pressure. The aim is to help students handling them more easily. Few experiences deal with advanced fluid mechanics.
The virtual laboratories aiming to reproduce experiences are simulations of the real world. They are used here in the framework of a computer learning environment. In order to rationalize our approach, we want to design a environment that should be as generic as possible.

\subsection{Learning}

The central issue of a CLE is learning. Different learning theories exist. The main ones are behaviourism, cognitivism and constructivism [9], [5]. For reminder, these theories can be briefly defined as follows.

In the behaviourist model, learning takes place when the individual gives a correct answer (has the expected behaviour) to a given stimulus. The human being is then considered as a passive being whose behaviours are determined by the environmental conditions.

In the cognitivist approach, learning is the process that leads to the integration of new information in memory (this theory accords a great importance to the different memory systems). The notion of information processing is introduced.

In the constructivist approach, learning is considered to be the result of an interaction between the subject and the environment. According to thit theory, the individuals that are confronted to a new situation will use ideas and processes that depend on previous knowledge representations. Learning is thus perceived as an active knowledge construction process rather than a knowledge acquisition process.

According to [8], the conception of interfaces for learning runs into some well known difficulties of cognitive psychology, among which the fundamental difference that lies between information and knowledge. It is said in [8] that "information is the rational treatment of objective, material and symbolic, manipulable and storable data". When "knowledge is the subjective internal state of these data, produced through assimilation and mental auto-transformation". The learning problem consists to manage to help the learner to cross this gap that separates objective data and subjective interiorization. Following Linard [8] who wrote: "from the conception side, the only possible strategy to avoid incoherencies between these dimensions is to process them together from the start. In order to achieve that, the priorities must be inverted et reckon to the interface and the screens an essential role in the system architecture", special attention was fiven to the interface.

\subsection{Simulations}

There exist a certain number of methodologies able to support learning. Some exemples are: tutorials, games, tests, tools and simulations. An educational simulation can be defined as a model of some phenomenon or ac- 
tivity that users learn about through interaction with the simulation [1].

In addition to simplifying models, educational simulations may add elements that are not present in the real world. Coaching, providing feedback or hints, and similar techniques help make complex phenomena or procedures easier and more comprehensible to beginning learners. Still according to [1], simulations have a certain number of advantages when compared to other methodologies :

- More motivating: learners are expected to be more motivated by active participation in a situation than by passive observation.

- Enhance transfer of learning: transfer of learning refers to whether skills or knowledge learned in one situation are successfully applied in other situations. Simulations have good transfer of learning if what was learned during the simulation results in improved performance in the real situation.

As explained in [1], there are several different approaches when using simulation as a tool to problem solving. They are: physical, iterative, procedural and situational.

- physical simulation: «In physical simulations a physical object or phenomenon is represented on the screen, giving the user an opportunity to learn about it. All physical simulations are intended to inform learners about some object or phenomenon and its underlying principles. We learn from physical simulations by manipulating the various objects or variables and observing how the overall system changes as a result. »

- Iterative Simulations: Iterative simulations are quite similar to physical simulations in that they teach about something. The primary difference is the manner in which learners interact with the simulation. Instead of continuously manipulating the simulation as it unfolds in either real or manipulated time, the learner runs the simulation over and over, selecting values for various parameters at the beginning of each run, observing the phenomena occur without intervention, interpreting the results, and then running it all over again with new parameters values. Time is generally not included as a variable in iterative simulations. That is, whether real phenomenon occurs very quickly or very slowly, in iterative simulations the learner manipulates parameters, runs the simulation, and sees immediate results.

As explained further, the experience about the Newton laws clearly belongs to the physical simulation category, as does the experience about the fluid mechanics. However, the chromatography is more of the iterative kind.

\subsection{Problem Frames}

Generally, the problems that occur in the framework of software development are large and complex, and it is often judicious to try and structure the original problem in a certain number of smaller and simpler subproblems. Using problem frames consists in defining different simple problem classes. "A problem frame defines a shape of a problem by capturing the characteristics and interconnections of the parts of the world it is concerned with, and the concerns and difficulties that are likely to arise" [4]. Problem frames thus allow one to focus on the problem, and not on the solution. A problem frame defines a class of recurring problems that are intuitively identifiable. It is important to underline some problem frames characteristics. First, the subproblems they define should be considered as projections of the original problem, as opposed to a partition of that problem. This means that some its aspects can be found in several different problem frames. During a subproblem analysis, it is a good idea to consider the other subproblems as being resolved. Furthermore, they form a parallel structure. The notion of parallelism is important in order to understand well the problem frames concept. Indeed, because of that parallelism, it is necessary to take into account all the interactions that can occur between subproblems.

\section{Application to the SAI project}

The SAI project's bounds can be identified with a context diagram. A context diagram involves the machine domain and the problem domains. It also specifies the interfaces between these domains. The SAI project's context diagram is presented in figure 1 .

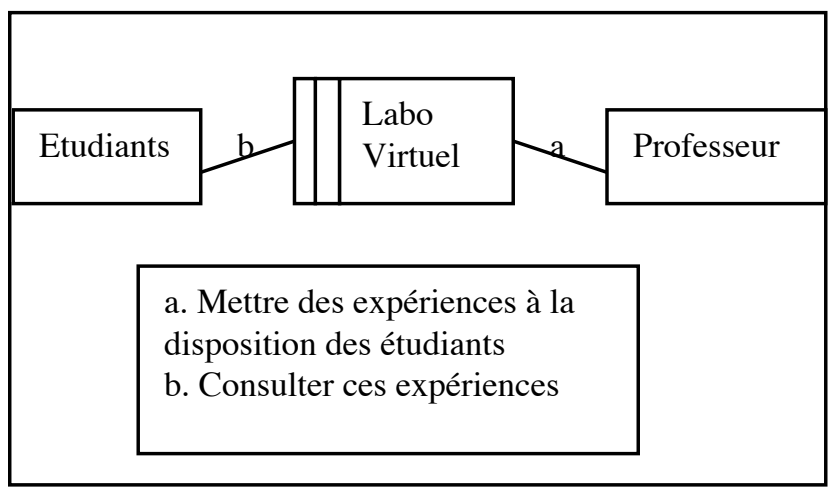

Figure 1 : Context diagram of the SAI project

This very simple diagram can certainly be adapted to numerous learning programs. It puts in presence all the actors and expresses clearly this project's main objective.

The next step, according to [4], is to decompose the main problem into smaller and simpler subproblems. In the framework if the this project, we will proceed to this cut in several times. First, a first cut is made rather intuitively. As said above, this project has among other objectives to allow professors to put con- 
tent to their students' disposal. Consequently, it is logical to separate the professor and the learner aspects.

\subsection{First decomposition}

\section{- The professor part}

The problem diagram of this part is shown in figure 3 . A problem diagram extends the context diagram by adding the requirements to the problem context, and so provides a starting point for problem analysis.

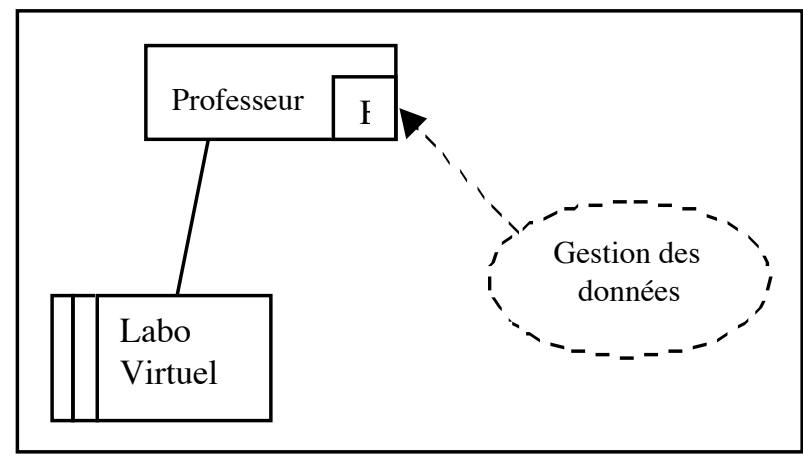

Figure 2 : Problem diagram for the professor part

The professor part can in its turn be divided into simpler and smaller subproblems. Indeed, a number of use cases can be defined that are true whatever experience is concerned. Among those, we will simply mention some of the main ones:

- relate an experience,

- modify an experience,

- $\quad$ access a student's result to assess them.

This part of the program is very important since it will have a direct influence on the student part. Since it is the professor who is in charge of the creation of the experiences, it is absolutely necessary to put at his disposal a tool that take the requirements formulated at the learner level into account. That's why the considerations expressed in the framework of the decomposition into subproblems of the learner part are essential and will largely influence the conception of the professor part.

\section{The learner part}

Different reasons make this part problematic and complex. Firstly, as indicated in [20], the conception CLE is a multidisciplinary process that involves various domains such as computing, cognitive psychology, sciences, etc. Then, the phenomena that have to be analysed during software conception are more complex than they are for an information system. Some difficulties are particular to the realization of that type of CLE, such as controlling interaction, modularizing actions and communication processes, interpreting learners' actions from computer observable data, or taking the learners' individual characteristics and their knowledge into account.

This part, en terms of requirements expressed by the professor, can be considered at two distinct levels. First, there is the level of the manipulations that the student should be able to execute. Those must be defined with the professor for each experience according to his or her needs. That level is thus particular to every experience. Then there is the level that is common to all of them, and that concerns learning.

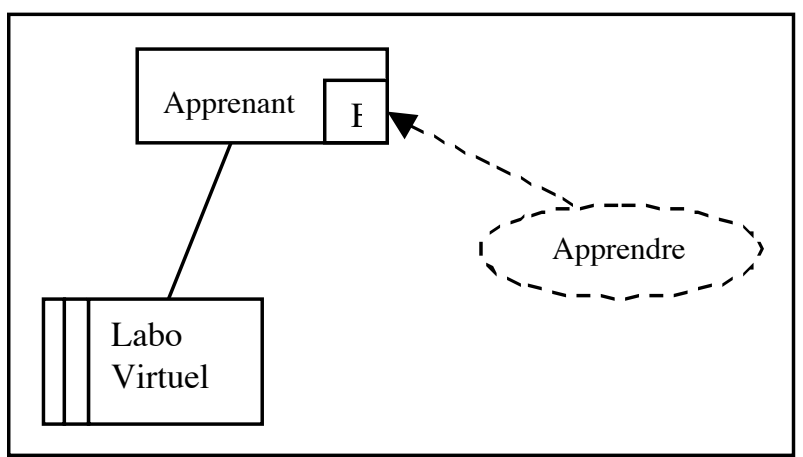

Figure 3 : Problem diagram for the learner part

This part's problem diagram, addressed under the learning angle, is in figure 3. This diagram shows that once more the requirement expressed about this program is simply a learning demand. The decomposition into subproblems is a little bit more complex. Indeed, the use cases that could be defined for this part would not be as relevant as they were in the professor part. It is certainly possible to identify a few ones, but at best they would address only part of the problem, and would certainly not have it completely covered.

"The problem should be decomposed into subproblems of recognizable and familiar classes" [4]. Furthermore, it is important to consider these problems as forming a parallel structure. The key to this approach is prior knowledge of the existing problem classes, of what's necessary solve them, and of the concerns that can occur for each of them [4].

Among the problem frames proposed in [4], none seems appropriate to cover the learning issue. Even though the "commanded behaviour frame" and the "simple workpieces frame seem to address the question partially, they both present a few shortcomings. Here is the intuitive idea describing the first one: "There is some part of the physical world whose behaviour is to be controlled by an operator. The problem is to build a machine that will accept the operator's commands and impose the control accordingly." In this case, the machine's behaviour must clearly be defined in advance. But part of the system we want to realize must contain some incertitude in order to allow the learner to commit mistakes or make discoveries. This problem frame might be appropriate

\footnotetext{
${ }^{1}$ Several problem schems are presented in [m5]. Each has an intuitive idea described by a short text.
} 
for the chromatography, and maybe also for fluid mechanics, but certainly not for the Newton laws.

Here is the intuitive idea describing the simple work pieces frame: "A tool is needed to allow a user to create and edit a certain class of computer-processable text or graphic objects, or similar structures, so that they can be subsequently copied, printed, analysed or used in other ways. The problem is to build a machine that can act as this tool". In that case, it is more question of the creation and the edition of reusable objects, when in our project no such thing is present on the student's side.

No existing problem frames seems to correctly fit our problem. Therefore, we propose three new problem frames: the manipulation, the simulation, and the learning. For each, the corresponding intuitive idea and problem diagram are presented.

\section{Simulation frame}

There exists a model of a real world phenomenon whose behaviour is to be simulated The problem is to build a machine that simulates that behaviour (figure 4).

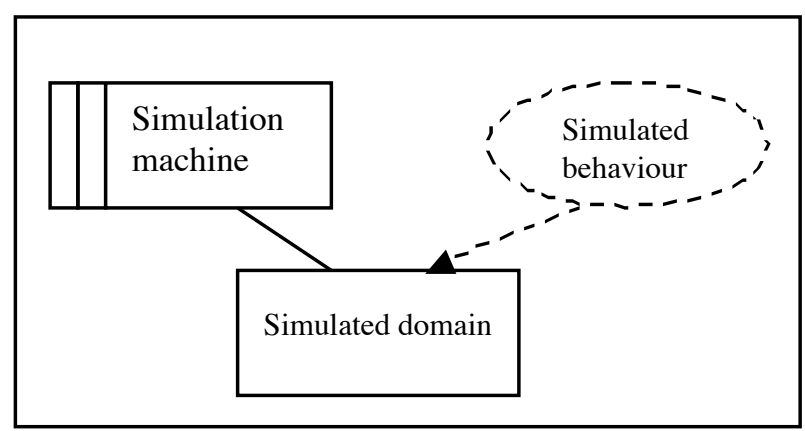

Figure 4 : Problem diagram of the simulation frame

Manipulation frame: it is possible to manipulate and define parameters for objects put at the user's disposal. The objects' behaviours change according to the parameters. Defined by the user The problem is to build a machine that allows the user to define different parameters and realize different manipulations. The corresponding problem diagram is presented in figure 5 .

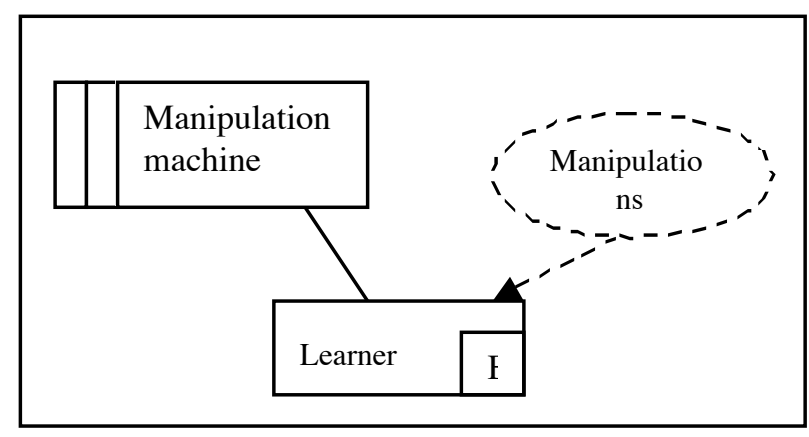

Figure 5 : Problem diagram of manipulation frame

\section{Learning frame}

A tool allowing a user to learn and discover is necessary. The problem is to build a machine that allows the user to learn. The problem diagram is shown in figure 6

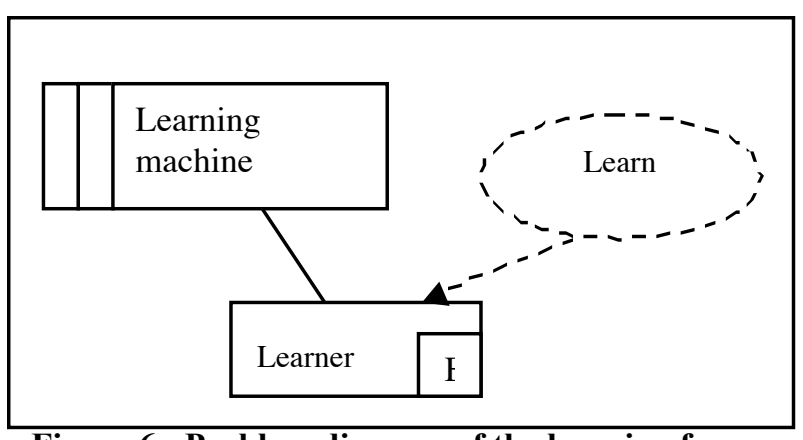

Figure 6 : Problem diagram of the learning frame

\subsection{Second decomposition}

Thanks to these new frames, we can proceed to the student part's decomposition into subproblems. However, as mentioned above, the different experiences involved in this project belong to different kinds of simulations. A consequence is that their decomposition is going to be different. Therefore, we will decompose each experience separately.

\section{Simulation}

One of the most important characteristics of simulations is that they demand an underlying model. The creators of a simulation must learn about the real phenomenon, must create and refine a computer model to simulate it, and must then incorporate that model into a program [1].

«A simulation doesn't just replicate a ph enomenon; it also simplifies it by omitting, changing, or adding details or features " [1]. Many simulation designers suggest that the more accurate the representation, the better the simulation. Although this may be true for simulations in engineering and research, it is not the case for educational simulations [1]. It is thus important, during a simulation's development, to choose carefully the level of details that is to be required, and not overload the mental charge, which is important in the case of a cognitive process. Thi lead us to the concept of parcimonious model

A parcimonious model must represent suitably behaviour of the system that must be studied. If educational program, he aspects that are included in the material to be presened must be well reproduced, and other aspects, if possible, must be absent of the model. Inplementing this, is said to be a parcimonious modeling approach, and the simulation requires minimal and compatible elements. Our subject of study is of a system hose behaviour is represented by mathematical models under the form of a dynamic system. In future it could be useful to examine special techniques to obtain such parcimonious models [3]. 
Applied to the SAI project, these considerations have driven us to make a certain number of decisions. Indeed, reproducing exactly the physical phenomenon described by the Newton laws would be an extremely complex task. Consequently, some phenomena have been simplified with the professor's agreement. Among those, let's mention collisions, gravity, or frictions. The simulation we are realizing is thus based on a simplified model of the Newton laws. For reminders, these laws are respectively named law of inertia, law of motion and law of reciprocal actions.

\section{Manipulation}

The manipulation frame involves a very important notion in the framework of learning: learner control. Some recommendations are:

- The most important learner control concerns sequence (which includes moving forward, moving backward, and selecting what to do next), and pace.

- Always allow learner control of forward progression

- Allow the user to review always that is possible.

- Always allow the learner temporary termination of a program. This means being able to temporarily end the program and return to it later.

- For general capabilities, such as directions, help, glossaries and temporary termination, provide the learner with consistent global control available everywhere in the program.

- Give learners with more content experience greater control than those with little content experience.

- $\quad$ Base learner controls on content. One should generally provide more learner control for problem-solving and higher-order thinking skills and more program control for procedural learning and simpler skills.

Recommendations for the modes of control:

- Use the mouse whenever possible as the primary mode of control

- Use the keyboard as a secondary mode of control, especially for expert users

- Use buttons for local and very frequent actions

- Use menus for global controls and selection of program sections

From these recommendations, we have established the following book of specifications for our project. A certain number of objects are put to the learner's disposal. The project is constructed around these objects that constitute its base. The students can select them in the laboratory with a mouse, they can move them and adjust numerous parameters. Each object has its own behaviour, and different objects can interact with each other.

\section{Learning}

Despite the decomposition into subproblems, the learning issue stays present. As is remembered in [8], the learning act has an "irreducible difficulty". Furthermore, as has been said earlier, a major problem comes from the central object that has to be considered, which is learning. The main objective of any learning environment setup is always learning, and that objective is difficult to define.

The HELICES model proposed in [8] allows one to define in a coherent way a few essential properties that a learning centred interface should have. We will rapidly mention the ones that seem to be most appropriate in this project's framework:

- Initial orientation and motivation : the opening screens must bring answers global questions such as: Who? Where? What? When ? How ? Why?

- Local auto test: the evaluation functions or screens offer for each important addressed point an immediate and simple feedback means, about individual performance quality at that point of the learning process.

- Repetition and systematic MISE EN VALEUR of invariants and objects and events variations under different situations is an efficient incentive to make access to generalization and to formalization of great relations between causes, effects and conditions easier.

Somee recommendations are proposed in [1]. Hereafter follow the ones we consider to be most pertinent with regard to the subject of this project: We will also underline the interesting remarks present in [1] about the necessity of feedback, and about the different forms of feedback that are to be provided.

At all levels, it is essential that different functions be accessible and understandable. Screens' design thus should stay sober and explicit, carried by a stable structure that avoids any cognitive overload due to information, hypertext or any other visual or audible effects excess [8]. In fact, hypertext has proven, in several instances, to be very useful as an interace to computer based learning environments [19], [2].

\section{Our Case of Study}

\subsection{The Newton laws}

This experience is decomposed into three subproblems: 
- $\quad$ simulation of the Newton laws - the Newton laws model is to be simulated by the machine;

- manipulation of objects - objects with different possible parameters like a mass, an angle, a cord have to be available for manipulation;

- learning of the presented concepts - the program should help the learner to understand the Newton laws.

\section{Simulation of the Newton laws}

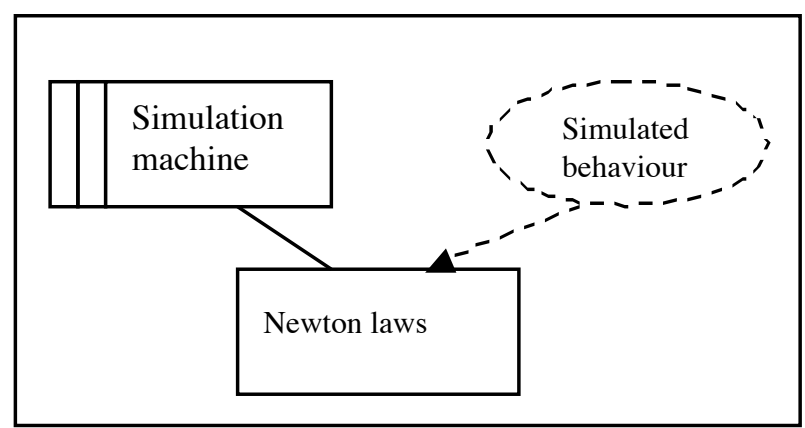

Figure 7 Context diagram for Newton laws

\section{Simulation}

This simulation is based on the model of the Newton laws. Going into the implementation's details would be beyond the scope of this paper. Therefore we will just give, as a reminder, a brief description of the three laws and how they were translated into software. The law of inertia: every object in a state of uniform motion tends to remain in that state of motion unless an external force is applied to it. The law of dynamics:

The relationship between an object's mass $\mathrm{m}$, its acceleration a, and the applied force $\mathrm{F}$ is $\mathrm{F}=\mathrm{ma}$. Acceleration and force are vectors (as indicated by their symbols being displayed in slant bold font); in this law the direction of the force vector is the same as the direction of the acceleration vector. The law of reciprocal action: for every action there is an equal and opposite reaction.

\section{Manipulation}

This experience consists in providing the following objects to the teacher: a bloc, a rope, a surface, a traction, a vector, a pulley. Different parameters can be applied to these objects, and they can interact with each other. The bloc has as characteristics a mass and a material. The surface has as well the material composing it as characteristic. A rope may have a weight or have none. A vector's parameters are its direction and its module. The teacher may arrange these objects the way he wants to, and design exercises for the students, who may consult these exercises and try to resolve them.

Among the interactions between these objects, let's mention the following ones: a bloc may slide along a surface, and its speed will depend such factors as mass, gravity, friction, etc; a rope can be attached to a pulley, and to a bloc; a pulley can be attached to a surface; etc.

When the learner is to solve an experience, he's supposed to associate the correct forces (vectors) to the different objects according to the problem's description. He may then test his solution, and analyse the resulting behaviour.

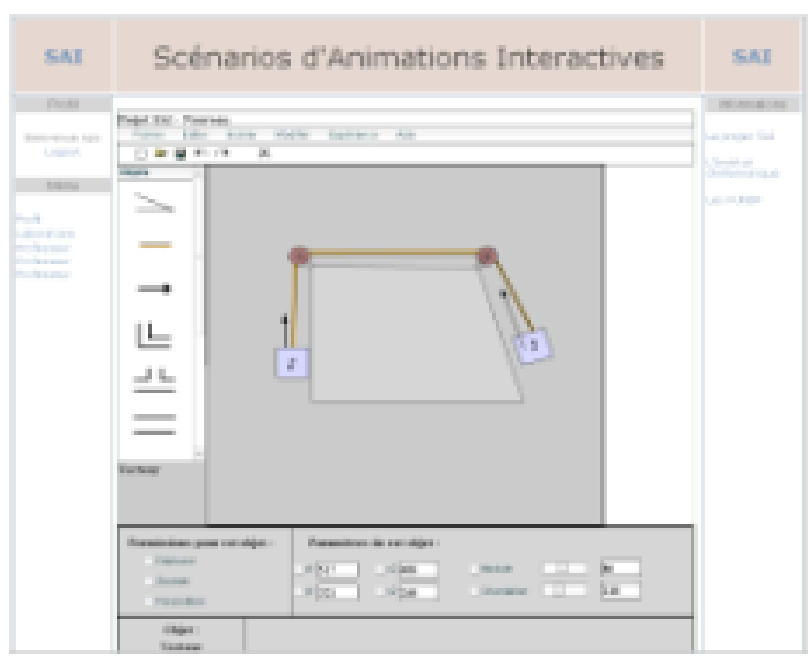

Figure 8: Newton Laws

\section{Learning}

With such a simulation, the student can learn form the errors he commits. Indeed, when the student is ready and decides to test the experience, the objects will move according to the Newton laws and to the vectors that were placed by the student. He will therefore be provided with an immediate visual feedback. So, not only will the student be able to assess the correctness of his choices, but he will also be able understand the consequences of the errors he committed.

With this experience, instruction is thus designed to facilitate extrapolation and fill in the gaps. This approach corresponds to the constructivist theory, since learning is considered an active process in which learners construct new ideas or concepts based upon their current/past knowledge. The learner selects and transforms information, constructs hypotheses, and makes decisions, relying on a cognitive structure to do so. Cognitive structure (i.e., schema, mental models) provides meaning and organization to experiences and allows the individual to "go beyond the information given".

\subsection{Fluid mechanics}

We have decomposed that experience into three problem frames: 
- $\quad$ simulation of fluid mechanics in stationary regime - this model has to be simulated by the machine;

- manipulation of objects - objects with different possible parameters like a pipe, an elbow, a pump have to be available for manipulation;

- learning of the presented conc the program should help the learner to understand the fluid mechanics in stationary regime.epts -

\section{Simulation in the Fluid Mechanics field}

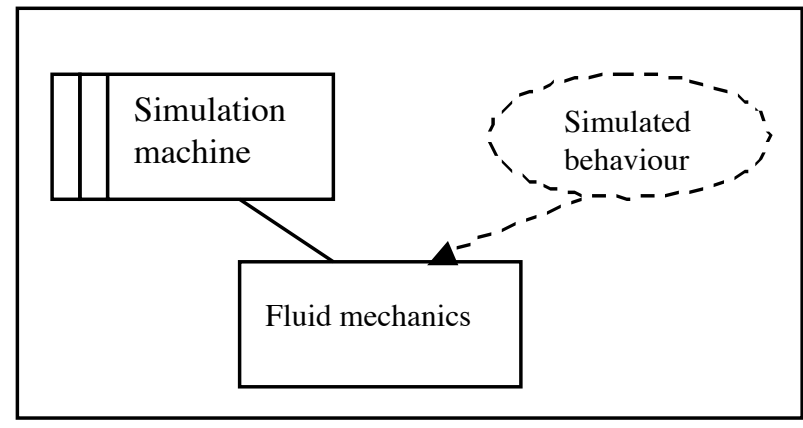

Figure 9: Context diagram for fluid mechanics

\section{Simulation}

This simulation is about fluid mechanics in stationary regime. The objective is to allow students to build the circuit of their choice, then put at different positions manometers and flow meters, so as to be able to know pressure and flow at these particular positions. Simulating fluid mechanics is not an easy task. So, the first simplification was to limit this experience's scope to stationary regime. The formulas used to compute flow for circuits containing at most two loops were implemented. When it comes to circuits containing more than two loops, the complexity involved is too big for this project's scope. Even though this limits the experience to quite simple circuits, the formulas involved are already quite complex.

\section{Manipulation}

Here, the student can build himself the experience, since he's responsible for the circuit's creation. To achieve this goal, different objects are available: a tube, a te, an elbow, a pump, a flow meter, and a manometer. Students have to respect at least two constraints when building a circuit: there has to one and only one pump and the circuit must be closed.

Different manipulations have been available to help students build circuits more easily. They can select different objects at the same time, move them, copy and paste them, and delete them. The undo/redo functions have been implemented, since a picture of the circuit is made every time an object is added to or deleted from the scene. Once the different objects have been brought to the scene, they can of course be modi- fied individually. When the user clicks on an element, the corresponding panel is displayed beneath the scene. Among the different parameters that can modify, there is the section (element's width), and the pump's initial pressure and flow. Furthermore, an attraction system has been put in place in order to facilitate construction. That system forces an element getting within another element's certain range to attach itself to that element. All circuits can be saved, and consulted later.

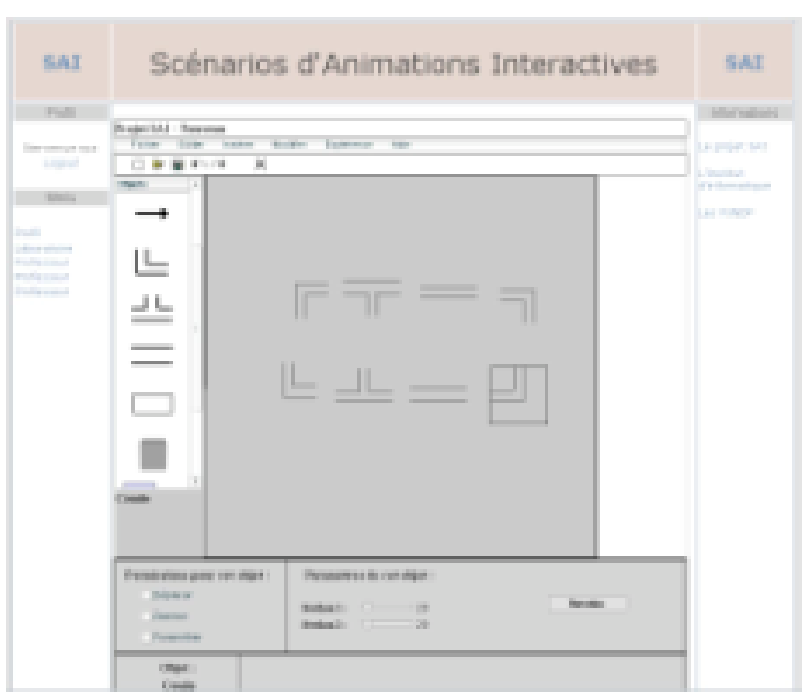

Figure 10 : Fluid mechanics

\section{Learning}

The pedagogical paradigm does not use the learning by a try and error style, since simulation does not allow them to commit any. This program is supposed to help them to understand the influence of different parameters on pressure and flow. Among these parameters, let's mention depth, pump pressure, and sections. This simulation is thus an interactive one. Indeed, instead of continuously manipulating the simulation, the learner can run the simulation over and over, selecting values for various parameters at the beginning of each run, observing the phenomena occur without intervention, interpreting the results, and then repeating them with new parameters values. Then, this simulation is similarto the cognitive approach because, in this case, learning involves associations established through contiguity and repetition. A key concept of cognitivism is the schema: internal knowledge structure. New information is compared to existing cognitive structures called "schema". Schema may be combined, extended or altered to accommodate new information.

\subsection{Chromatography}

The following decomposition has been applied to that experience:

- $\quad$ simulation of a model of the ion exchange chromatography - this model has to be simulated by the machine; 
- manipulation of objects - that experience has to offer the user the possibility to change different parameters;

- learning of the presented concepts - the program should help the learner to understand the influence of the parameters on the experience's results.

Simulation of Chromatography

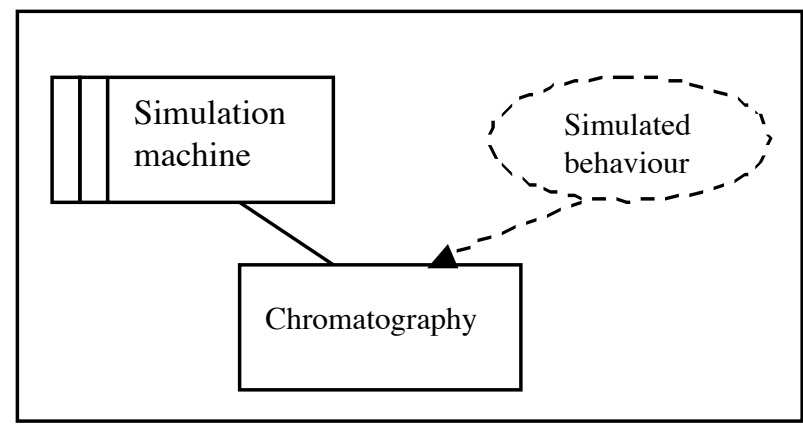

Figure 11 Context diaggram for chromatography

\section{Simulation}

The factors that intervene in the separation of molecules between the mobile phase and the stationary phase are numerous: solubility, size, shape, polarity, electric charge, presence of atom groups, etc. The combination of these factors is of course extremely complex and very difficult to compute. Therefore, it would have been too complex and even unnecessary to try to implement the effective reactions happening during an ion-exchange chromatography. The results have thus been recalculated and saved for each of these possibilities. They appear under a graphical shape. Consequently, no computation is realized when the experience is run. Furthermore, the results are obtained immediately, while in the case of a real chromatography, it may sometimes happen that up to a few hours are necessary before the experience ends and the results are available.

\section{Manipulation}

The possible manipulations are quite simple for chromatography. Indeed, this experience consists for the students to choose different values for the available parameters, and to analyse the resulting graphical result. There is only one object involved: the column. It has the same properties as any other object of this program. However, it offers only little possibility of manipulation, but many possibilities of parameterisation. The professor can decide the different parameters among which the learner will have to choose. And the learner can choose among these different parameters. Then he can run the simulation, which as a result displays a graphic.
Furthermore, the professor has the possibility to add new results. Indeed, he decides the range of values available for the different parameters, and he decides the results that are associated to a particular combination of parameters. The graphic is automatically created from the values entered by the professor.

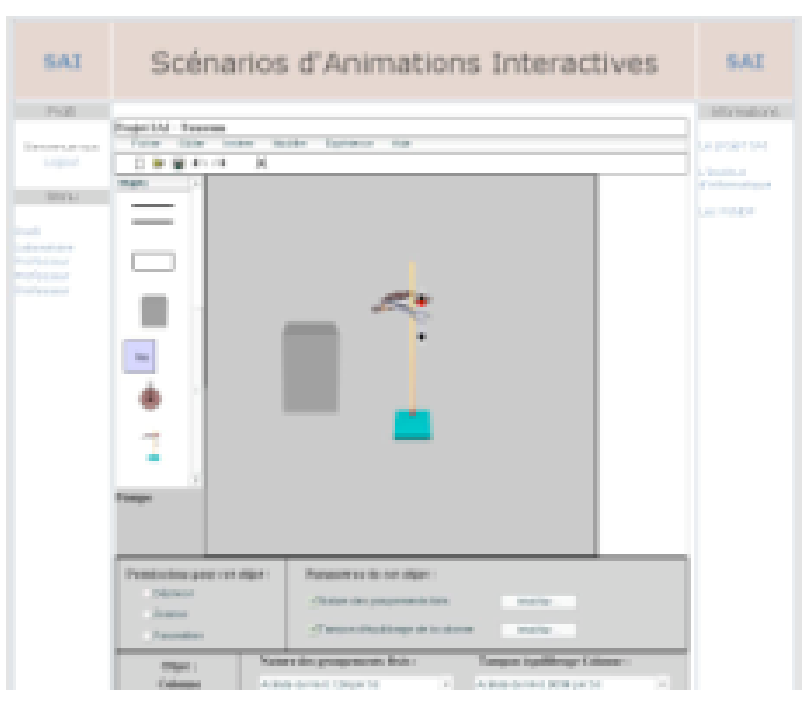

Figure 12 : Ion exchange chromatography

\section{Learning}

This simulation again belongs to the interactive kind. However, here, the students are not simply supposed to make measures, but they are expected to find the parameters that will optimally solve the problem. Errors can thus be committed, and the students are to understand where their errors lie according to the results they get after they run the experience. With this experience, the possibility is offered to the students to run as many tests as they want, which would not be the case in reality, since ion-exchange chromatography is not an immediate phenomenon. So, they can analyse carefully and understand the influence of each parameter on the result. This should definitely help them to master the quite difficult theories explaining this experience.

\section{Discussion}

We have presented a way to address the conception of computer assisted learning environments with the problem frames approach. This method has been applied to the SAI project, and to the three experiences composing the project. This approach allowed the decomposition of the main problem into subproblems and thento be able to tackle them separately. Nevertheless, according to [20], the construction of a CLE requires an interactive conception process's (even participative), with numerous and controlled experiments. These are often used in order to test the assumptions and to support the conception process. 
"Experimentation then becomes more than just a phase used to improve a product, but a key element of the conception process, and even a conceptualisation method with successive prototypes".

Furthermore, at this level a more practical but unavoidable problem appears: the experimentation of a CLE supposes not only a simple maquette, but an advanced prototype, maybe even a finished product [20]. Indeed, the completeness of the functionalities, as well as the quality and robustness of the ergonomics and interface are strictly necessary. It is not possible to try and assess a CLE through asking a learner "not to pay attention to the interface" or to the fact that some functionalities have not been implemented yet.

These elements converge in the same direction, which is the need to consider the placement of the interfaces at the heart of a CLE's development.

The decomposition into subproblems presented in this paper has lead us to the same conclusions. Indeed, the learning demand is irreducible and intrinsequely tied to the interface. And that demand is a full part of the problem, and thus influences the place of the interfaces' conception. They should not be considered as secondary, but are of the utmost importance.

\section{Acknowledgements}

This project was supported by grants from the Wallon Region and United Europe through the structure «First Europe ». Our european e partenaire is SEMM ("Service d'Enseignement sur Mesure Médiatisé ») from the Lille1 University, whose experience in the development of multimedia material for learning pourposes of physics was an invaluable factor for the success of the project. Their material and knowledge supports are acknowledged.

\section{Bibliography}

[1].ALESSI, S. M. \& TROLLIP, S. R. Multimedia for Learning, Methods and Development. Allyn \& Bacon, 2001.

[2].ANGELONI, M. N. M.; KREUTZ, L. S.; BARRETO, J. M.:. Técnicas de Simulação e Hipermídia Aplicadas ao Ensino na Area Médica. In: CBEB'2000,. XVII Congresso Brasileiro em Engenharia Biomédica. F. M. de Azevedo, J. L. B. Marques, I. Cestari, (edts.), v. 2, Florianópolis, p. 1069-1973,. 2000.

[3].BARRETO, J. M.; NOIRHOMME-FRAITURE, M.; LIMA, W. C. de.: Minimal and Compatible Models through Bond Graphs. In: II Congresso Latinoamericano de Controle Automático, Buenos Aires. 1986.
[4].JACKSON, M. Problem Frames: Analysing and structuring software development problems. Addison-Wesley Professional, $1^{\text {st }}$ edition, 2000.

[5].KEARSLEY, G., Explorations in Learning \& Instruction: The Theory Into Practice Database http://tip.psychology.org/

[6].LEFÈVRE，J.; FABRI，R; BARRETO, J. M.; NOIRHOMME-FRAITURE, M.: The Coupling of Simulation, CAI and Expert Systems: a Prospective Study. Micro-Professeur, v. 2, p. 42-50, 1985.

[7].LEFÈVRE, J.; BARRETO, J. M.: Didatic Micr ocomputer Simulation in Cardiac Dynamics. In: 5th Annual Conf. on Frontiers of Eng. in Health Care (IEEE), Colombus, Ohio. 1983.

[8].LINARD, M. Concevoir des environnements pour apprendre : l'activité humaine, cadre organisateur de l'interactivité technique. In Delozanne, E. \& Jacobini, P. Interaction homme-machine pour la formation et l'apprentissage humain, Sciences et techniques éducatives, vol 8, n³-4, p. 211-238, 2001.

[9].MERGEL, B., Instructional Design and Learning Theory, Educational Communications and Technology, University of Saskatchewan, 1998 http://www.usask.ca/education/coursework/802pa pers/mergel/brenda.htm

[10].MURRAY, T. Authoring Intelligent Tutoring Systems: An Analysis of the State of the Art. International Journal of Artificial Intelligence in Education Vol. 10, p 98-129, 1999.

[11].NDAYE, M., VANCLEVE, J., CALMANT, P., PIROTE, C., HOUSEN, I., de BAENSTVANDENBROUCKE, A., ROUSSELET, D., VANDENHAUTE, J., DEPIEREUX, E., NOIRHOMME-FRAITURE, M., MAI : An Authoring System for Designing Interactive Learning Modules, Institut d'Informatique, FUNDP, Namur, Belgium, Unité de Recherche en Biologie Moléculaire, FUNDP, Namur, Belgium, 2003.

[12].PAGANO, R. L.; BARRETO, J. M.. Computer Simulation + Information Tecnology: Good Tools for Classroom Work?. In: $9^{\text {th }}$ Int. Conf. on Technology and Education - ICTE'92, 1992, Paris, 1992.

[13].PAGANO, R. L.; BARRETO, J. M.; LEBACQ, J.: Microcomputer Simulation of Biological Systems as an Educational Tool in Medicine. In: ISMM'91. Proc. of Inter. Conf. Mini and Microcomputers in Medicine and Healthcare. Inter. Soc. for Mini and 
Microcomputers, D.l. Hudson (ed.), Long Beach, California, p. 9-12, 1991.

[14].PAGANO, R. L.; BARRETO, J. M.. Hypertext Information Tecnology in Medical Education. In: MELECON'91 IEEE Mediterranean Electrotecnical Conference, 1991, Lyubjana. IEEE, Baldomir Zacj, Franc Solina (editores), 1991.

[15].PAGANO, R. L.; BARRETO, J. M.: Laboratory Experiment Simulation in Electrical Engineering Education. In: 3rd European Simulation Congress, Edinburgo, p. 311-317, 1989.

[16].PAQUETTE, G., CREVIER, F. \& AUBIN, C. Méthode d'ingénierie d'un système d'apprentissage (MISA). Centre de recherche LICEF, Télé-université, 1996.

[17].PIERRE, S. et LAOUAMRI K. Laboratoires Virtuels pour l'Enseignement des Sciences et de la Technologie (LVEST). Laboratoire de recherche en réseautique et informatique mobile (LARIM), Département de génie informatique, École Polytechnique de Montréal, 2004.

[18].PLATO Learning, http://www.plato.com/

[19].POZZEBON, E.; VEDANA, S. B.; ALMEIDA, M. A. F.; BARRETO, J. M.. Hipermídia Aplicada ao Ensino na Área Médica. In: $C B E B^{\prime} 2002, X V I I I$ Congresso Brasileiro em Engenharia Biomédica, São José dos Campos - SP., 2002.

[20].TCHOUNIKINE, P. Pour une ingénierie des Environnements Informatiques pour l'Apprentissage Humain. . In Revue I3 information - interaction intelligence 2(1), www.revue-i3.org, 2002. 